\title{
Plasmodium vivax within European borders
}

\author{
Aitor Olaso-Bengoechea ${ }^{1}$, María F López-Ballero ${ }^{2}$ and Teresa Ferrer-Gimeno ${ }^{3}$ \\ ${ }^{1}$ Public Health Inspector, Sección Sanidad Ambiental, Instituto Salud Pública y Laboral Navarra (ISPLN), Spain \\ ${ }^{2}$ Medical Doctor, Hospital San Juan de Dios, Pamplona, Spain \\ ${ }^{3}$ Head of Section Sanidad Ambiental, Instituto de Salud Pública y Laboral Navarra (ISPLN), Spain
}

Malaria disease [1] is a life-threatening infectious disease caused by parasites of the Plasmodium genus, transmitted through the bite of the infected female Anopheles mosquito. Among the five [1] parasites species that cause malaria in humans (Plasmodium falciparum, $P$. vivax, $P$. ovale, P. malariae and $P$. knowlesi), two [2] pose the greatest threat: P. falciparum is responsible for $99 \%$ of malaria deaths globally and, $P$. vivax, represent the most dominant malaria parasite in most countries outside of sub-Saharan Africa.

Common symptoms of malaria are high fever, headache, diarrhoea, chills and vomiting, which may manifest themselves in some 1-4 weeks after infection. P. falciparum malaria causes anaemia and, left untreated, may rapidly progress to severe illness and death. On the contrary, $P$. vivax malaria is less aggressive, but could relapse, which may occur months and in some cases, to years later.

Nowadays, it is a preventable and curable disease but, a fully tested vaccine is not yet authorised in any region in the world. In Europe, malaria remains a rare [3] disease in terms of prevalence, but existence of $P$. vivax malaria occurred [4] since the first outbreak [1] in Greece in 2009.

Although malaria was eradicated from Greece in the 1970's [5], different factors such increasingly temperature warming might favour mosquito proliferation and parasite development, together with new risks [4] such are massive refugee's crisis and migrant populations flow from endemic or epidemic areas could contribute to building up of a $P$. vivax reservoir. From 2009, P. vivax malaria has re-emerged $[1,4]$ in areas of Greece that were hotspots of malaria before its eradication, in persons without travel history to a malaria endemic country. Autochthonous [3] malaria occurs when a human is infected in a malaria-free area, which has been transmitted by a vector-borne (Anopheles mosquito) from another human who has been previously infected from a malaria endemic or epidemic area. A number of Public Health measures were implemented since 2012 [4] to prevent reestablishment of the disease in the country.

Table 1 shows the number of total malaria cases in the last 5 years (period 2012-2016), overall remaining less of a hundred cases yearly and includes imported malaria cases of $P$. vivax and $P$. falciparum in the

Copyright: (C2017 Olaso-Bengoechea A. This is an open-access article distributed under the terms of the Creative Commons Attribution License, which permits unrestricted use, distribution, and reproduction in any medium, provided the original author and source are credited.
Table 1. Total malaria cases reported from 2012-2016 in Greece

\begin{tabular}{|c|c|c|c|c|c|c|}
\hline \multirow{3}{*}{ Year } & \multicolumn{5}{|c|}{ Plasmodium species } & \multirow{3}{*}{$\begin{array}{c}\text { Total } \\
\text { malaria } \\
\text { cases }\end{array}$} \\
\hline & \multicolumn{3}{|c|}{ P.vivax } & \multirow{2}{*}{$\begin{array}{l}\text { P.falciparum } \\
\text { (imported) }\end{array}$} & \multirow{2}{*}{$\begin{array}{c}\text { Other/ } \\
\text { Unspecified } \\
\text { (imported) }\end{array}$} & \\
\hline & Total & Imported & Autochthonous & & & \\
\hline 2012 & 74 & 54 & 20 & 16 & 3 & 93 \\
\hline 2013 & 12 & 9 & 3 & 12 & 1 & 25 \\
\hline 2014 & 6 & 6 & 0 & 31 & 1 & 38 \\
\hline $2015^{\mathrm{a}}$ & 20 & 19 & $1^{\mathrm{c}}$ & 9 & 1 & 30 \\
\hline $\mathbf{2 0 1 6}^{\mathrm{b}}$ & 68 & 63 & 5 & 19 & 1 & 88 \\
\hline
\end{tabular}

${ }^{a} U p$ to $26 / 8 / 2015$

bUp to $12 / 9 / 2016$

${ }^{\mathrm{c}}$ There were 6 cases at the end of the year [4]

whole period. Also, it includes the total $P$. vivax cases and $P$. falciparum cases. All $P$. falciparum cases were imported malaria, whereas $P$. vivax malaria cases combined imported and autochthonous cases. Zero local-acquired autochthonous malaria was reported in 2014 only.

In conclusion, it can be said that autochthonous malaria remains active in Greece since 2009, with an exception of zero cases reported in 2014. Among all malaria cases in Greece (imported and autochthonous), all autochthonous cases were caused by Plasmodium vivax. This autochthonous malaria presence may suggest an existing $P$. vivax parasite reservoir in the area together with existence of the mosquito vector, probably boosted by the European refugee crisis and migration flow. This situation will need further surveillance.

\section{References}

1. Hellenic Center for Disease Control \& Prevention (HCDCO). Epidemiological Surveillance Report. Malaria in Greece.

2. World Health Organisation (2016) World Malaria Report 2016. WHO Press, Geneva, Switzerland.

3. Olaso A, de Górgolas M, Ramos JM (2015) Malaria in Europe: a rare disease? Gac Sanit 29: 316-317. [Crossref]

4. Olaso A, Ramos JM, López-Ballero MF, Olaso I (2016) Malaria in Europe: Follow-up of autochthonous malaria in Greece and new risks. Enferm Infecc Microbiol Clin 11: 003. [Crossref]

5. Piperaki ET, Daikos GL (2016) Malaria in Europe: emerging threat or minor nuisance? Clin Microbiol Infect 22: 487-493.
Correspondence to: Aitor Olaso-Bengoechea, Public Health Inspector, Sección Sanidad Ambiental, Instituto Salud Pública y Laboral Navarra (ISPLN), Spain, E-mail: aitorolaso@gmail.com

Received: July 19, 2017; Accepted: August 02, 2017; Published: August 06, 2017 